\title{
QUILOMBO COMO UM CONCEITO EM MOVIMENTO OU QUILOMBISMO E UBUNTU: PRÁTICAS ANCESTRAIS AFRICANAS PARA REPENSAR PRÁTICAS PEDAGÓGICAS E DE JUSTIÇA
}

\author{
QUILOMBO AS A CONCEPT IN MOTION OR QUILOMBISM AND \\ UBUNTU: AFRICAN ANCESTRAL PRACTICES TO RETHINK \\ PEDAGOGICAL AND JUSTICE PRACTICES
}

\author{
Aline Cristina Oliveira do Carmo ${ }^{1}$
}

\begin{abstract}
Resumo: Partindo dos estudos de Beatriz Nascimento [1985; 1987], que compreende o quilombo como um conceito em movimento, pretendo apresentar algumas reflexões sobre a importância dessa compreensão para repensarmos nossas práticas pedagógicas e de justiça. No campo da justiça, esse conceito permite a compreensão dos processos de formação de quilombos históricos e contemporâneos na África e na diáspora. No diálogo com as teorias da justiça e da educação, esse conceito também permite a identificação da filosofia ubuntu (Ramose, 1999; São Bernardo 2016) nesses territórios, na medida em que a identidade e os modos de fazer dessas comunidades são fundamentalmente coletivos e interdependentes. Nesse sentido, o quilombismo, tal como defendido por Abdias Nascimento [1980], possibilita a identificação e desenvolvimento de práticas pedagógicas calcadas em saberes ancestrais de matriz africana que tenham como intuito o fortalecimento desse tipo de humanidade expresso nos quilombos, que (só) se compreende em uma coletividade, cuja dinâmica existencial se dá em movimento e unidade com os elementos da natureza. Seguindo a perspectiva de valorização desses saberes e práticas, os estudos aqui compartilhados demonstram a potencialidade de repensarmos nossas práticas pedagógicas e de justiça, tomando por base o modo de vida expresso e valorizado em territórios quilombistas, a fim de alimentar mundos em que nossa dignidade plena seja efetivamente contemplada.
\end{abstract}

Palavras-chave: Quilombo. Justiça. Ubuntu. Saberes Ancestrais.

\begin{abstract}
Based on the studies by Beatriz Nascimento [1985; 1987], who understands quilombo as a concept in motion, I intend to present some reflections on the importance of this understanding in order to rethink our pedagogical and justice practices. In the field of justice, this concept allows the understanding of the processes of formation of historical and contemporary quilombos in Africa and the diaspora. In the dialogue with the theories of justice and education, this concept also allows the identification of ubuntu philosophy (Ramose, 1999; São Bernardo 2016) in these territories, considering that the identity and ways of doing these communities are fundamentally collective and interdependent. In this sense, quilombism, as advocated by Abdias Nascimento (1980), enables the identification and development of pedagogical practices based on ancestral knowledge of African origin that aim to strengthen this type of humanity expressed in quilombos, which is (only) understood as a collectivity, whose existential dynamics occurs in movement and unity with the elements of nature. Following the perspective of valuing these knowledges and practices, the studies shared here demonstrate the potential to rethink our pedagogical and justice practices, based on the
\end{abstract}

1 Doutorado em Filosofia (UERJ, 2016). Colégio Pedro II - Departamento de Filosofia. E-mail: alinec.oliveira1984@gmail.com 
mode of humanity expressed and valued in quilombista territories, in order to feed worlds in which our full dignity is effectively contemplated.

Key words: Quilombo. Justice. Ubuntu. Ancestral knowledge.

\section{Introdução}

Pretendo compartilhar neste artigo algumas breves pistas e reflexões de percurso que venho desenvolvendo, a partir de uma investigação ainda incipiente, sobre as relações entre quilombismo e ubuntu. Considerando tratar-se de conceitos bastante complexos em si mesmos, buscar relacioná-los parte de um esforço quase utópico em dar sentido a expressões de africanidade na diáspora, especialmente quando se manifestam em formas próprias de organização social, que atualizam um modo específico de compreender e valorizar nossas comunidades, fundado em uma filosofia praticada por diferentes povos africanos e afrodiaspóricos.

Por essa razão, é fundamental reconhecer as limitações dessa investigação desde o início, uma vez que a condição diaspórica implica em lidar com histórias fragmentadas pelo racismo colonialista, que insiste em tentar exterminar conhecimentos ancestrais que nos permitem romper com sua lógica de dominação. Por consequência, esse escrito também se revela fragmentado, incompleto, mas ao mesmo tempo dinâmico, isto é, sujeito a movimentações de idas e vindas, afirmações e revisões - expressão que igualmente revela uma forma africana de se compreender a vida, como um fluxo contínuo, sempre dinâmico, sujeito a alterações e atualizações, tendo em vista a garantia da potência de vida de nossas comunidades.

Nesse sentido, parto de alguns dos muitos estudos historiográficos de Beatriz Nascimento sobre os quilombos, buscando destacar sua compreensão do termo como um conceito em movimento - o que é evidenciado pelas diferentes significações que assume ao longo da história, não apenas na diáspora, como no próprio continente africano. Entre esses pontos de conexão dos diversos coletivos negros de resistência, está o papel desempenhado por mulheres no desenvolvimento de práticas de resistência de suas comunidades, tendo em vista a garantia de seus territórios e modos de vida.

Passando da abordagem sobre os quilombos históricos do período colonial para os dias atuais, reflito brevemente sobre o significado da legislação brasileira destinada ao reconhecimento e proteção dos direitos dessas comunidades e seus territórios como políticas de justiça, tanto frente ao Estado, quanto internamente no que tange à sua gestão comunitária. Nessa perspectiva, ganha relevo a concepção de quilombos contemporâneos, a qual corrobora 
com a noção de quilombo desenvolvida por Beatriz Nascimento, para além de uma compreensão restrita e de caráter colonial como "comunidade de negros fugidos". Por fim, a abordagem do quilombismo proposta por Abdias Nascimento, enquanto conjunto amplo de práticas de resistência cultural negra sob a forma de modos próprios de organização social, indica a possibilidade de identificação na atualidade de redes educacionais quilombistas, caracterizadas pela articulação de diferentes práticas pedagógicas voltadas para a emancipação de comunidades negras, com base em valores culturais de base africana. Dentre esses valores, destacam-se os vinculados à filosofia ubuntu, termo de origem bantu que abarca uma compreensão ampla sobre o significado de humanidade, incluindo gerações passadas, atuais e futuras, bem como todos os elementos da natureza.

\section{Quilombo como um conceito em movimento}

Historiadora de formação, Maria Beatriz Nascimento nasceu em Sergipe em 1942 e possui vasta produção intelectual, cujo acervo encontra-se em parte atualmente no Arquivo Nacional do Rio de Janeiro, que possui um fundo no qual guarda mais de 160 itens da autora, bem como uma biblioteca que leva seu nome ${ }^{2}$. Em sua produção, encontramos desde trabalhos historiográficos e sonoros, até poemas, ensaios, estudos e um filme ${ }^{3}$ que levam a reflexões de caráter profundamente filosófico. Entre seus temas de investigação, os quilombos se destacam como um elemento recorrente de suas preocupações. Em muitos dos seus artigos sobre o tema, um ponto importante ressaltado consiste na multiplicidade de significados do termo quilombo adotados ao longo da história, variando conforme os sujeitos e propósitos de suas definições, bem como suas contextualizações sociais, políticas e culturais. A preocupação da autora em rastrear as origens e alterações desses sentidos revela igualmente sua preocupação em superar lacunas e distorções sobre o tema e, ao mesmo tempo, recuperar o protagonismo africano e afrodiaspórico na conformação de seus modos próprios de organização social e política - de forma a romper com abordagens tipicamente coloniais sobre os quilombos.

No artigo "O conceito de quilombo e a resistência cultural negra" [1985] a autora apresenta como seus objetivos no texto a caracterização do quilombo como uma instituição africana, de origem angolana e pré-diaspórica; as diferentes conotações adquiridas pelo termo no Brasil colonial e imperial, até sua caracterização como resistência cultural negra na

\footnotetext{
${ }^{2}$ http://arquivonacional.gov.br/br/component/tags/tag/maria-beatriz-nascimento . Acessado em 27.06.2020.

${ }^{3}$ GERBER, Raquel e NASCIMENTO, Maria Beatriz (1989). ÔRÍ [cinta cinematográfica]. Brasil, 131 minutos.
} 
contemporaneidade (2018, p.273). Com esse intuito, parte de uma crítica à historiografia ocidental marcada pela exotização do continente, para explicar o modo como o kilombo se constitui como instituição africana, pelo menos desde o século XVI, com a formação da sociedade Imbangala:

\begin{abstract}
A sociedade guerreira Imbangala era aberta a todos estrangeiros, desde que iniciados (...), incorporando jovens de várias linhagens na mesma sociedade guerreira. Kilombo aqui recebe o significado de uma instituição em si. Seria Kilombo os próprios indivíduos ao se incorporarem à sociedade Imbangala. O outro significado estava representado pelo território ou campo de guerra que se denominava java. Ainda outro significado para Kilombo dizia respeito ao local, casa sagrada, onde processava-se o ritual de iniciação. $\mathrm{O}$ acampamento de escravos fugitivos, assim como quando alguns Imbangalas estavam em comércio negreiro com os portugueses, também era Kilombo. (...) [O] que difere entre quilombos do século XVII dos demais era a possibilidade de grupos e etnias comuns ainda poderem ser encontrados num espaço territorial e voltados para um tipo de economia, o que dá a medida de risco que representavam para o sistema colonial. Podemos mesmo afirmar que esses quilombos são o primeiro momento da nossa história que o Brasil assim se identifica enquanto Estado centralizado (...). É enquanto caracterização ideológica que o quilombo inaugura o século XX. (...) [J]ustamente por ter sido durante três séculos concretamente uma instituição livre, paralela ao sistema dominante, sua mística vai alimentar os anseios de liberdade da consciência nacional (...). A retórica do quilombo, a análise deste sistema alternativo, que serviu de símbolo principal para a trajetória deste movimento. Chamamos isto de correção de nacionalidade. (NASCIMENTO, B., 2018, p.280; 283; 289-291).
\end{abstract}

Seguindo essa mesma compreensão, no artigo “introdução ao conceito de quilombo", publicado em 1987, encontramos estudos que confirmam o caráter mutável (mas nem por isso esvaziado) do termo:

Essa indefinição a respeito do que seja um quilombo levou historiadores a ampliar seu conceito. (...) Essas variações também foram sofrendo modificações através do tempo como imaginário histórico e social. (...)

Compreendendo o quilombo em seu sentido histórico, diríamos que ele se transformou num instrumento ideológico e num sistema social alternativo. É importante, pois, que se reproduza sua trajetória para o entendimento de seu aparente desaparecimento da História do Brasil a partir do final do século XIX e das sobrevivências ou diferenças que ele projetou no século XX (NASCIMENTO, B., 2018, p.303-304;307).

Contemporaneamente, de acordo com a normativa atualmente vigente no Brasil, as comunidades remanescentes de quilombos (assim denominadas pelo artigo 68 do Ato das Disposições Constitucionais Transitórias da Constituição brasileira de 1988) consistem em 
grupos étnico raciais, segundo critérios de auto-atribuição, com trajetória histórica própria, dotados de relações territoriais específicas, com presunção de ascendência negra relacionada com a resistência à opressão histórica sofrida (BRASIL, 2003). A respeito dessa definição, notase que a legislação não define essas comunidades com base na denominação colonial relativa à fuga. Isso porque o fundamento dessa compreensão está no critério de autodefinição, princípio fundamental que marca um rompimento com a perspectiva colonial em que a caracterização dessas comunidades partia de sujeitos externos às mesmas. Sendo assim, a legislação atual brasileira ultrapassa uma compreensão restrita referente aos considerados quilombos históricos (como Palmares) e passa a abarcar os chamados quilombos contemporâneos, isto é, todos aqueles capazes de atender aos requisitos indicados na legislação acima referida, englobando comunidades formadas por descendentes de escravizados situadas em diferentes localidades e com formas diversas de organização social. Atualmente, estima-se a existência de mais de três mil dessas comunidades por todo o país ${ }^{4}$. Com isso, pode-se observar que a atual legislação brasileira sobre quilombos acompanhou os estudos desenvolvidos por Beatriz Nascimento, que já apontavam para a necessidade de rompimento com a compreensão colonial de "escravos fugidos".

Dessa forma, não obstante as alterações dos sentidos vinculados ao termo ao longo do tempo, a autora indica a existência de elementos de continuidade histórica que permitem a identificação de determinados espaços como quilombos ontem e hoje, tendo como principal elemento demarcador dos mesmos o caráter de resistência cultural negra, presente em manifestações culturais tais como o reinado em determinadas comunidades do país, em terreiros de candomblé e até mesmo em favelas e no Teatro Experimental do Negro.

$\mathrm{O}$ fato desses espaços se constituírem em alternativas a uma sociedade pautada pelo racismo, subordinação e extermínio de sua negritude aponta para a habilidade da população afrodiaspórica em constituir comunidades nas situações mais adversas, capazes não apenas de ameaçar a sociedade hegemônica, como também de perpetuar saberes ancestrais de base africana que dignificam suas existências e contribuem efetivamente para a vida de seus membros e comunidades, em sentido amplo. Cabe então reconhecer que saberes e tecnologias ancestrais foram e são mobilizados por essas comunidades para a garantida da vida em seus territórios, a despeito das constantes tentativas de desumanização de suas populações e de extermínio, apagamento ou clandestinização de seus saberes (MIRANDA, 2017) até os dias

\footnotetext{
4 Cf. http://cpisp.org.br/direitosquilombolas/observatorio-terras-quilombolas/quilombolas-brasil/ . Acesso em 13.07.2020.
} 
atuais.

\section{Mulheres negras mobilizadoras de saberes ancestrais em prol da vida de suas comunidades}

Sobre a constituição de lideranças nos quilombos, diversas autoras têm demarcado o papel singular da presença de lideranças femininas em comunidades negras de resistência. Lélia Gonzalez (2018) escreve sobre Nanny, rainha quilombola dos maroons na Jamaica. Nah Dove (1998), em seus estudos sobre mulherismo africana, destaca a longa trajetória de mulheres negras e africanas no seu papel de gestoras de suas comunidades, não apenas no âmbito doméstico, como também na organização econômica, administrativa e militar de seus territórios. Nesse sentido, é importante observar que o caráter coletivo de organizações negras de resistência (isto é, de enfrentamento ao genocídio) e de re-existência (ou seja, de organização própria para garantia de suas vidas e liberdade em condição de dignidade $)^{5}$ abrange como prática e tecnologia ancestral uma ampla valorização das habilidades físicas e intelectuais de seus membros, independentemente de seus gêneros. Isso quer dizer que o que importa para essas comunidades são as contribuições dessas pessoas para a garantia da continuidade dos valores considerados fundamentais para sua reprodução física e cultural.

A esse respeito, Beatriz Nascimento aponta para a importância do desenvolvimento de uma pesquisa que trate especificamente sobre o papel da mulher nos quilombos:

[M]esmo na escassa bibliografia e nas poucas fontes primárias disponíveis e levantadas por poucos autores, inclusive nós, vez por outra, surgem referências de nomes de mulheres nos quilombos, seja como massa, seja na política como chefes, guerreiras, mineração ou conselheiras, geralmente destacadas por ser mãe ou irmã de chefes masculino[s] (Aqualtune e Acotirene em Palmares) e trabalhadores (as mulheres do Quilombo Grande).

Se os homens nos quilombos praticavam a guerra e o deslocamento territorial constante, tanto em África como na América (Brasil, Guianas, Cuba, Haiti, Jamaica etc.), as mulheres, as poucas citadas participam como integrantes destes esforços. (...) $\mathrm{O}$ estudo do quilombo, enquanto comunidade sobrevivente, vem sendo feito em diversos estados brasileiros. $\mathrm{O}$ papel da mulher, pelas razões apresentadas, não deve estar ausente do esforço de reconstituição histórica do processo de desenvolvimento da resistência negra (NASCIMENTO, B., 2018, p. 410).

Dessa forma, a autora destaca a importância de se compreender o papel das mulheres

\footnotetext{
${ }^{5}$ Cf. ACHINTE, 2013, p.443-468.
} 
negras como força atuante ao criar alternativas à escravização negra.

Na mesma direção, afirma Lélia Gonzalez:

\begin{abstract}
Nanny está para a Jamaica assim [como] Zumbi está para o Brasil. (...)
E Nanny não é exaltada apenas por seus poderes sobrenaturais, mas por sua liderança militar que se impõe na questão da paz com os ingleses. Tendo lhe proposto a paz, num primeiro encontro, os bakra tiveram suas condições rejeitas por Nanny. Mas, numa segunda vez, ela aceitou o tratado de paz, o que despertou forte oposição de seu mais importante capitão (...). Que se pense na decisão de Nanny como uma crítica ao militarismo extremado que acaba por ameaçar a sobrevivência do próprio grupo. E só poderia ter partido de uma mulher a significativa atitude de aceitar a paz, sobretudo num momento em que a comunidade sofria sério risco em face do avanço bakra, como sugere a estória (GONZALEZ, 2018, pp. 338; 340-341).
\end{abstract}

Mais além do contexto colonial, muitos são os estudos existentes sobre o papel de mulheres negras e africanas como lideranças e mantenedoras dos valores culturais de suas comunidades no contexto africano e afrodiaspórico, pré-colonial e contemporâneo, especialmente no que tange à sua gestão econômica e administrativa, bem como no desenvolvimento de práticas educativas. Dadas as limitações desse trabalho, não cabe aqui desenvolver esse ponto, porém é fundamental constatar como um traço recorrente de comunidades africanas e afrodiaspóricas o papel de mulheres negras como lideranças fundamentalmente coletivas, a despeito da misoginia e da subordinação feminina preconizadas pelo patriarcado, enquanto elemento estruturante do regime colonial imposto e herdado contemporaneamente. Isso pode ser observado nos trabalhos de diversas autoras, tanto de feministas negras (como Angela Davis e Lélia Gonzalez) como de mulheristas africanas (como Nah Dove e Anin Urasse), além de importantes intelectuais africanas que vão além dos estudos de gênero, como a socióloga nigeriana Oyèrónkẹ Oyěwùmí [1997].

\title{
Rastreando possíveis relações entre filosofias ancestrais africanas, ubuntu e quilombismo
}

A atuação de lideranças femininas negras focadas em garantir a vida de suas comunidades, mais do que simplesmente a vida dos indivíduos que as compõem de forma (supostamente) isolada, revela a presença de um sentido particular de comunidade que vale aqui demarcar. Segundo Wanderson Flor do Nascimento:

A noção de comunidade que se afirma nos modos de vida e no pensamento das sociedades tradicionais africanas é bem distinta do modo de afirmá-la no Ocidente moderno, sobretudo quando pensada por um viés liberal. Enquanto no último, tal 
noção aparece quase sempre dicotomizada em relação à percepção de individualidade, nas primeiras ocorre um fenômeno inverso: há uma radical contiguidade entre o que seja a comunidade e o que seja o indivíduo-sujeito-pessoa: não há pessoas sem comunidade e não há comunidade sem pessoas. (NASCIMENTO, 2020, p. 41).

Observando como traço comum dos estudos aqui referenciados a existência de elementos demarcadores de uma unidade cultural africana (DIOP, 2014), destaco como um desses elementos a existência de uma percepção de mundo caracterizada por "uma espécie de interligação fundamental entre todas as coisas existentes" (NASCIMENTO, 2020, p. 41). Nesse sentido, cabe ressaltar esta como uma das importantes contribuições de filosofias africanas e afrodiaspóricas, que nos auxilia a repensar práticas pedagógicas e de justiça, para além de uma concepção antropocêntrica ou dicotômica entre humanidade e natureza, ou ainda, entre homens e mulheres.

No filme Orrí, Beatriz Nascimento critica, com relação aos estudos negros, o que caracteriza como um "eterno estudo sobre o escravo" (2018, p.328) e destaca a raiz NTU da palavra bantu ${ }^{6}$, enquanto termo que denota um sentido relacional profundo, presente na filosofia expressa nos quilombos.

O QUEÉ A CIVILIZAÇÃO AFRICANA E AMERICANA? É um grande transatlântico. Ela não é civilização Atlântica, ela é Transatlântica.

Foi transportado para América um tipo de vida que era africana. É a transmigração de uma cultura e de uma atitude no mundo, de um continente para outro, de África para América. (...)

Essa textura do Banto, essa rede de relações que o Banto estabelece na África, entre as várias etnias, está fundamentada na própria raiz da língua Banto, que é a raiz NTU. O sentido de NTU é a relação de pessoa para pessoa. Os homens se comunicam através daquela raiz e se conhecem entre si, na África, por esse radical da sua própria língua nacional.

Sabemos que o quilombo é de origem Banto, sabemos que a dinâmica Banto acompanha toda a filosofia, todo o ethos do quilombo, o comportamento do quilombo. (Ibid., p.327; 329).

Dessa forma, ela aponta para o quilombo como um tipo de agregação ou comunidade que expressa um sentido de nação tipicamente africano e bantu, na medida em que se trata de uma perspectiva fundamentalmente relacional de um modo de vida, baseado na

\footnotetext{
${ }^{6}$ Considerando que os textos aqui citados variam no uso da grafia para se referenciar ao tronco lingüístico originário e aos povos falantes de línguas bantas, entendemos como mais pertinente respeitar as variações utilizadas por cada autor/a e, no corpo deste artigo propriamente dito, seguir a grafia do termo raiz NTU e, assim, grafar o termo sobre a forma bantu. Ao mesmo tempo, entendemos que as respectivas variações na escrita do termo por autores africanos e afrodiaspóricos são igualmente coerentes com a perspectiva africana da pluriversalidade, que rechaçam abordagens filosóficas redutoras da multiplicidade e complexidade da vida.
} 
interdependência de seus membros e de todos os elementos que compõem a comunidade.

No que tange aos efeitos éticos e políticos dessa compreensão ontológica e epistemológica bantu sobre o que significa humanidade e comunidade, Sérgio São Bernardo afirma que

\begin{abstract}
A ideia de Ubuntu, como princípio de equilíbrio e harmonia é um valor inestimável para se pensar o "renascimento africano". Temos que combater um entendimento comum de que a lei era algo estranho aos povos africanos. A filosofia Ubuntu (Ubu é a ideia do ser em geral e Ntu o ser em particular), é ontológica e epistemológica, e pode indicar o surgimento da humanidade para os africanos de língua banto. A justiça Ubuntu se funda na crença de que os que ainda não nasceram, os seres vivos e os mortos viventes são os fundamentos de equilíbrio e verdade, para pensar o equilíbrio, em geral, a ideia de justo. A justiça restaurativa dos Banto, sediada no pensamento Ubuntu, garante o equilíbrio. A injustiça sobrevive à lei. No direito Ubuntu, as pessoas que o ferem devem acertar as contas com o tempo e a memória da comunidade. (SÃO BERNARDO, 2016, p. 67).
\end{abstract}

Nesse sentido, a filosofia ubuntu dialoga com a perspectiva de uma justiça restaurativa, através da qual o conflito não é negado, buscando-se a restauração da comunidade como um todo após a violação sofrida. Isso se dá com base em uma compreensão de humanidade que extrapola (e muito) a noção de indivíduo racional e sujeito atomizado da filosofia modernacolonial (supostamente humanista), uma vez que compreende uma noção ampla de comunidade, que envolve não apenas indivíduos, como também suas gerações passadas, presentes e futuras, além de todos os elementos da natureza.

Dessa forma, as autoras e autores aqui trazidos problematizam a persistência de percepções racistas que negam a importância da filosofia africana na contemporaneidade e propõem um olhar para o presente e futuro de nossas comunidades com base no resgate e desenvolvimento de práticas e saberes ancestrais de base africana. Distante do iluminismo europeu, cujo suposto humanismo é denunciado por seu caráter genocida, o quilombo, tal como aqui estudado, revela a expressão de uma concepção de humanidade fundamentalmente ligada à comunidade.

Avançando nessa compreensão, o filósofo congolês Bas'llele Malomalo demarca uma importante crítica às compreensões do ubuntu reduzidas ou centradas em uma noção restrita de humanidade:

A filosofia do $\mathrm{Ntu}$, defendida por mim, não denuncia somente o antropocentrismo ocidental, mas igualmente as diferentes formas dos antropocentrismos presentes nas interpretações exógenas e endógenas das 
culturas africanas. Nesse sentido, compreende que a filosofia bantu de Temples (2012) errou ao afirmar que a cosmovisão africana é antropocêntrica. Não concorda também igualmente com as interpretações, como a de Kashindi (2017), que reduzem ubuntu à humanidade. Pelo contrário, é mais do que isso: é a ontologia africana assente no Ser-sendo (RAMOSE, 2002, 2011), Bisoidade Cósmica ou Vida Cósmica da qual os seres humanos são somente uma parte mínima (MALOMALO, 2018). (...) É o Ntu que dá vida a Tudo o que existe. Na filosofia africana ancestral, tudo o que existe é movimento, interconexão, integração e interdependência entre os seres. (...) A própria palavra Ntu significa Vida/Força ou Energia; Ubuntu que Ramose traduz por Ser-Sendo, deve se traduzir, como sempre faço, em Vida-Força-emMovimento (MALOMALO, 2019, p.81-82; 87).

Nesse ponto, observamos mais uma vez as noções de movimento e interdependência como elementos fundamentais que caracterizam a filosofia ancestral africana. Isto ocorre porque, como observado pelo filósofo sul-africano Mogobe Ramose (2011, p.17), o movimento constitui um princípio do Ser-Sendo, percepção de mundo presente em diversas filosofias africanas, desde Kemet (Egito antigo) até a contemporaneidade.

A respeito da importância da noção de movimento na filosofia africana, esse autor apresenta uma importante distinção:

\begin{abstract}
O raciocínio circunscrito, ou seja, o raciocínio e a ação sobre as bases das fronteiras já estabelecidas e das ainda-por-estabelecer, corrobora a experiência de que tudo está em fluxo. Trata-se de uma condição de incessante mudança e mutabilidade porque o movimento, e não o repouso, é o princípio do ser. Ser é estar na condição de -dade e não de -ismo. Esta é a base ontológica da tensão subseqüente entre -dade e -ismo. (...) Certamente o -ismo é apenas um momento, não eliminação ou a substituição da - dade. Como forma de ilustração, apresento a filosofia ubuntu dos direitos humanos. (...) O ubuntu é, ontologicamente, uma -dade e não um -ismo. Enquanto tal, está epistemologicamente orientado em direção à construção de um conhecimento que é, na sua essência, não-dogmático. (...) O ubuntu é um dos conceitos filosóficos e dos princípios organizacionais essenciais das populações que falam línguas Bantu. Essas populações precisam, face à organização econômica, cimentar fortes vínculos de solidariedade, em primeiro lugar entre elas mesmas. Aqui, o desiderato por solidariedade é, de facto, a consideração de uma fronteira. (RAMOSE, 2010, pp.178-179).
\end{abstract}

Observando a formação de diferentes organizações comunitárias negras voltadas para a constituição de redes de solidariedade mútua com o intuito de garantir a emancipação cultural e política de suas comunidades, Abdias Nascimento sistematizou sob o termo quilombismo as experiências de resistência cultural negra e suas respectivas formas de organização social e política ao longo da história. 
O quilombismo se estruturava em formas associativas que tanto podiam estar localizadas no seio de florestas de difícil acesso, facilitando sua defesa e sua organização econômico-social própria, como também podiam assumir modelos de organizações permitidas ou toleradas, frequentemente com ostensivas finalidades religiosas (católicas), recreativas, beneficentes, esportivas, culturais ou de auxílio mútuo. Não importam as aparências e os objetivos declarados (...). Genuínos focos de resistência física e cultural. Objetivamente, essa rede de associações, irmandades, confrarias, clubes, grêmios, terreiros, centros, tendas, afoxés, escolas de samba e gafieiras foram e são os quilombos legalizados pela sociedade dominante; do outro lado da lei se erguem os quilombos revelados que conhecemos. Porém, tanto os permitidos quanto os "ilegais" foram uma unidade (....). A esse complexo de significações, a essa práxis afro-brasileira, eu denomino quilombismo (NASCIMENTO, A., 2019, p.281-282).

Sendo assim, é possível identificar, dentre outros, ao menos dois pontos de conexão entre práticas quilombistas e a filosofia ubuntu: a noção de interdependência entre humanidade e comunidade (entendida em sentido amplo por Malomalo (2019, p.76) como a comunidadeuniverso-natureza, a comunidade-sagrado-ancestral e a comunidade-de-bantu ou humanos), e a constituição de redes de solidariedade mútua (internamente entre seus membros e externamente entre apoiadores e comunidades similares, movidas pelo mesmo propósito). Além disso, o fato de desde a origem os quilombos possuírem o caráter de comunidades abertas para sujeitos de diferentes origens sociais e étnicas indica sua conformidade como outro elemento de caracterização do ubuntu que, de acordo com o filósofo congolês, está sempre em movimento e aberto para o outro, numa perspectiva de diálogo intercultural crítico, tendo "por finalidade a emancipação cósmica, isto é, de todos seres viventes visíveis e invisíveis”(Ibid., p.82).

Quanto aos possíveis impactos dessa compreensão para o campo da educação, Claudia Miranda, Fanny Riascos e John Arboleda (2016) propõem um aprofundamento na compreensão do quilombismo, a fim de desenvolverem o que denominam como pedagogias quilombolas:

São análises urgentes nas quais se enfatiza na necessidade de revisar o chamado cânone ocidental, para a organização da transposição didática e da prática educativa nas universidades. Por fim, nossa defesa é que a mudança de posição ou status de todo o chamado 'resto do mundo' está diretamente relacionado a outro referencial teórico. Para a Diáspora Africana, especificamente, é urgente fortalecer um corpo conceitual próprio, à maneira de Pedagogias Quilombolas. Para este quadro que estamos propondo, incluímos a noção de "Quilombismo" colocada por intelectuais e ativistas afro-brasileiras/os em suas estratégias de composição de redes (Devés-Valdés, 2008), organizando-se a partir de coletivos, associações e fóruns, já que o Quilombo dos Palmares consolida estes vínculos ao longo da história de resistência quilombola. Quilombismo significa mover-nos em direção às nossas raízes, rever os caminhos que temos feito sem vontade de fazê-los (porque foram processos violentos) e estabelecer vínculos fundamentais para 
preservar, conhecer e construir outros referentes para a Diáspora Africana. Trabalhar para essa tarefa é adotar o Quilombismo, o qual também está presente em diferentes regiões do planeta. (MIRANDA, RIASCOS, ARBOLEDA, 2016, p.27-28, tradução nossa).

Dessa forma, eles ressaltam não somente a capacidade de sobrevivência e resistência de populações que enfrentam a violência racial nas suas mais diversas expressões, como também revelam o caráter criativo e propositivo desses povos, através da formação de redes de cooperação mútua, destinadas à emancipação política e cultural de suas comunidades. Nesse sentido, a constituição e fortalecimento de redes educacionais quilombistas pode se tornar inspiração para o desenvolvimento de práticas pedagógicas interculturais críticas. Essas redes podem ser entendidas como redes de contato e intercâmbio entre educadores e ativistas de diferentes formações, que têm por um de seus objetivos principais (não obstante suas estratégias diversas), a emancipação da população africana e afrodiaspórica, através de práticas educativas voltadas para a disseminação de valores culturais de base africana. Abertas para o aprendizado mútuo entre os diferentes sujeitos que as compõem, essas iniciativas de solidariedade fortalecem a valorização e disseminação de sistemas sociais alternativos, destinados ao fomento de um equilíbrio cósmico entre todas as formas de vida.

Ao colocarmos as/os autoras/es ora estudadas/os em diálogo, é possível identificar a existência de um fundamento ético, ontológico e epistemológico - o ubuntu - que permite uma compreensão das práticas quilombistas como expressão de ser em movimento, sempre em diálogo com as todas as formas de vida, consideradas como dotadas de um valor moral intrínseco.

Sendo assim, a mobilização estratégica de conceitos como quilombismo e ubuntu indica a existência de caminhos, fundamentados em tecnologias ancestrais africanas, para o desenvolvimento de práticas pedagógicas e de justiça que permitem na contemporaneidade a valorização das vidas e dos saberes produzidos por povos integrantes da África Global ${ }^{7}$. Além disso, o desenvolvimento dessas práticas também é capaz de fortalecer o reconhecimento de contribuições fundamentais da filosofia africana para desafios do mundo contemporâneo como um todo, a partir de uma perspectiva intercultural crítica e dialogal com outras tradições culturais de pensamento, sobre os mais variados temas (tais como no campo da discussão sobre as violências decorrentes das hierarquias de gênero até questões relacionadas à ecologia

\footnotetext{
${ }^{7}$ Conceito proposto por Carlos Moore em conferência realizada no Rio de Janeiro em 2019, para designar a África continental e diaspórica, território de referência para o exercício do que denomina cidadania global-africana.
} 
profunda).

\section{Para não concluir - buscando o fortalecimento de redes educacionais quilombistas}

Beatriz Nascimento ressalta a importância de desenvolvimento de estudos sobre o que denomina paz quilombola, para além daqueles que enfatizam a perspectiva da guerra sobre esses territórios:

Outro desvio detectado é que a historiografia dá um enfoque extraordinário à guerra; cai sempre na análise de documentos oficiais, documentos de repressão. Neste particular, analisa o momento do ataque à ordem social vigente, aos estabelecimentos negros, inexistindo estudos fundados sobre os momentos de paz. Em pesquisas recentes, realizadas em várias universidades do Brasil, os estudiosos buscam reelaborar o conceito de paz quilombola. Como um estabelecimento humano, sofrendo o acossamento de uma ordem tão repressiva como a colonial escravocrata permitiria a paz concomitante com a guerra? Formulando melhor a pergunta: como estes estabelecimentos sobreviviam fora da ordem e ao mesmo tempo dentro dela? (NASCIMENTO, B., 2019, p. 304-305).

Considerando o atual momento de recrudescimento no Brasil e em diversas partes do mundo de movimentos de extrema-direita, neofascistas, de expressão nitidamente genocida especialmente contra populações negras e indígenas (e seus respectivos saberes e valores ancestrais), cabe fazer reverberar os questionamentos da autora sobre a possibilidade de estabelecermos a paz, mesmo em contextos marcados pela guerra. Cabe a nós, a meu ver, seguirmos as trilhas de nossas e nossos ancestrais em busca da paz quilombola, repensando nossas atitudes cotidianas nos campos da educação e da justiça, com base em saberes e tecnologias ancestrais de base africana que alimentam nossos processos de resistência e reexistência até os dias atuais.

Ora, dentre as informações que possuímos sobre os quilombos de ontem e hoje, mesmo ainda com dados dispersos sobre essas comunidades no continente e nas diásporas, o que sabemos é que foram e ainda são numerosos, e que constituíram efetivos sistemas alternativos de organização social e política, fundados em valores ancestrais de base africana. Logo, seguir as trilhas desses saberes pode nos levar ao desenvolvimento de práticas que fortaleçam e deem continuidades a essas iniciativas, e fortalecimento dos valores culturais a eles associados.

Ao expressar uma compreensão ampla sobre os sentidos de humanidade e comunidade, que engloba gerações passadas, presentes e futuras, além de todos os elementos da natureza, a 
filosofia ubuntu nos convida a pensar a educação de maneira holística, não fragmentada, com base no diálogo com a ancestralidade e outras matrizes culturais, tendo em vista o florescimento de nossas potências de vida. Em consonância com a filosofia ubuntu, o pensamento e práticas quilombistas não negam os conflitos, inerentes a toda vida em comunidade, mas buscam compreendê-los sempre com o intuito de garantir ou restaurar o equilíbrio social e a harmonia cósmica, mesmo diante das adversidades.

Considerar o quilombo como um conceito em movimento e o quilombismo como um conjunto de práticas de organização social e política destinadas à resistência cultural negra, e ambos os conceitos fundados no ubuntu, indica um caminho possível para fazer da nossa educação uma prática muito além da transmissão de conteúdos e da formação de um indivíduo para se tornar um cidadão ou um consumidor consciente. Trata-se de fazer dessa prática um lugar de reencontro consigo mesmo e com nossa ancestralidade, de abertura para o outro como um ser dotado de um valor intrínseco, mas também de abertura para o novo, através de uma releitura do passado e do presente, tendo em vista o reconhecimento de si mesmo como um elemento participante da natureza, cujo equilíbrio depende de sua harmonização com todos os elementos que contribuem para a garantia do nosso bem viver (MALOMALO, 2019).

Nesse sentido, a constituição e fortalecimento de redes educacionais quilombistas permite a valorização e a disseminação de sistemas sociais alternativos, destinados ao fomento de um equilíbrio cósmico entre todas as formas de vida.

Apesar de evidente, é necessário reconhecer que ainda há muito a dizer e realizar sobre as noções quilombismo e ubuntu e seus possíveis impactos nos campos da educação, da filosofia e do direito. Dadas as limitações deste artigo, muitos pontos importantes sobre esse debate não puderam ser abordados ou desenvolvidos. Dentre eles, destaco a noção de pensamento orgânico desenvolvida por Antonio Bispo dos Santos (2015); a importante investigação sobre o quilombismo como uma filosofia política em afroperspectiva desenvolvida por Lorena Silva Oliveira (2019); as conexões da filosofia ubuntu com a noção de direitos biocósmicos defendida por Bas'llele Malomalo (2019); a crítica de filósofos africanos e afrodiaspóricos aos usos considerados equivocados da filosofia ubuntu, tal como expresso, por exemplo, no estudo de Luís Saraiva (2019); a filosofia da ancestralidade desenvolvida por Eduardo David Oliveira (2007); a noção de interculturalidade crítica para o desenvolvimento de um diálogo de saberes de forma não epistemicida (WALSH, 2009), e o intenso debate sobre a aplicabilidade da filosofia ubuntu em teorias da justiça sobre reparação, reconciliação e restauração (CASTIANO, 2010 e SÃO BERNARDO, 2018), entre muitos outros. Sigamos em 
movimento.

\section{Referências}

ACHINTE, Adolfo Albán. Pedagogías de la re-existencia. Artistas indígenas y afrocolombianos. In. WALSH, Catherine (organizadora). Pedagogías decoloniales: prácticas insurgentes de resistir, (re)existir y (re)vivir. Tomo I. Quito: Ediciones Abya Yala, 2013.

BRASIL, Decreto Presidencial n 4.887. Brasília, 2003.

Constituição da República Federativa do Brasil. Brasília, 1988.

CASTIANO, José P. Referenciais da Filosofia Africana: em busca da intersubjectivação. Moçambique. Sociedade Editorial Ndjira, Lta, 2010. $1^{\text {a }}$ Edição.

DAVIS, Angela. Mulheres, raça e classe. São Paulo: Boitempo, 2016.

DIOP, Cheikh Anta. A Unidade Cultural da África Negra. Esferas do Patriarcado e do Matriarcado na Antiguidade Clássica. Luanda: Edições Mulemba, Outubro de 2014.

DOVE, Nah. Mulherisma Africana. Uma teoria afrocêntrica. Tradução de Wellington Agudá. Universidade Temple. In. Jornal de Estudos Negros, Vol. 28, № 5, Maio de 1998, 515-539. Sage Publications.

GONZALEZ, Lélia. Primavera para as rosas negras: Lélia Gonzalez em primeira pessoa... Diáspora Africana: Editora Filhos da África, 2018. 486 páginas. 1 ${ }^{\mathrm{a}}$ edição.

MALOMALO, Bas'llele. Filosofia africana do NTU a defesa de direitos biocósmicos. In: Problemata: Revista Internacional de Filosofia, V. 10. n. 2 (2019), p. 76-92. Disponível em https://periodicos.ufpb.br/ojs/index.php/problemata/issue/view/2407 . Acesso em 13.07.2020.

MIRANDA, Claudia, RIASCOS, Fanny Milena Quiñones y ARBOLEDA, John Henry. Pedagogías quilombolas y aprendizajes decoloniales en la dinâmica organizacional de las poblaciones negras. In: Revista da ABPN, v. 8, n. 18 • nov. 2015 - fev. 2016, p.25-43.

MIRANDA, Claudia. Clandestinización y resistência. In: Rosa Campoalegre Septien [et al.] Más allá del decenio de los pueblos afrodescendientes. Editado por Rosa Campoalegre Septien ; Karina Andrea Bidaseca. - 1a ed. - Ciudad Autónoma de Buenos Aires: CLACSO, 2017. (Antologías del pensamiento social latinoamericano y caribeño).

MOORE, Carlos. Qual o destino da África Global num século regido pela Inteligência Artificial, a Biotecnologia e o Grande Projeto inter-espacial? Aula magna em comemoração ao dia da África "25 de maio". Rio de Janeiro: UFRJ, 2019.

NASCIMENTO, Abdias. Quilombismo. Documentos de uma militância pan-africanista. Rio de Janeiro: Ipeafro, 2019.

NASCIMENTO, Maria Beatriz. Beatriz Nascimento, Quilombola e Intelectual: possibilidade nos dias da destruição. Diáspora Africana: Editora Filhos da África, 2018. 
NASCIMENTO, Wanderson Flor. Entre apostas e heranças: Contornos africanos e afrobrasileiros na educação e no ensino de filosofia no Brasil. Rio de Janeiro: NEFI, 2020 (Coleção Ensaios; 6).

OYĚWÙMÍ, Oyèrónkẹ. La invención de las mujeres. Una perspectiva africana sobre los discursos occidentales del género. Bogotá: En la frontera, 2017.

OLIVEIRA, Eduardo David de. Filosofia da Ancestralidade: corpo e mito na filosofia da educação brasileira. Curitiba: Editora Gráfica Popular, 2007.

OLIVEIRA, Lorena Silva. O quilombismo: uma expressão da filosofia política afroperspectivista. In. Problemata: Revista internacional de filosofia. V. 10. n. 2, 2019, p. 128146. Disponível em https://periodicos.ufpb.br/ojs/index.php/problemata/issue/view/2407 . Acesso em 13.07.2020.

RAMOSE, Mogobe B. Globalização e Ubuntu. In: SANTOS, Boaventura de Sousa e MENESES, Maria Paula (orgs.). Epistemologias do Sul. São Paulo: Cortez, 2010, pp. 175220.

RAMOSE, Mogobe. Sobre a legitimidade e estudo da filosofia africana. In: Ensaios Filosóficos, Volume IV - outubro/2011, pp. 9-25.

SANTOS, Antônio Bispo. Colonização, quilombos. Modos e significados. UnB: Brasília, 2015.

SÃO BERNARDO, Augusto Sérgio dos Santos de. Kalunga e o direito: a emergência de uma Direito inspirado na ética afro-brasileira. In. Hendu. Revista latino-americana de direitos humanos. Belém: UFPA, $2016 . \quad$ Disponível https://periodicos.ufpa.br/index.php/hendu/issue/view/308 Acesso em 13.07.2020.

. Kalunga e o direito: a emergência de uma justiça afro-brasileira. Tese de doutorado multi-institucional e multidisciplinar em difusão do conhecimento. Salvador: UFBA, 2018. Disponível em https://filosofia-africana.weebly.com/textos-diaspoacutericos.html . Acesso em 13.07.2020.

SARAIVA, Luís Ferreira. O que e quem não é ubuntu: crítica ao "eu" dentro da filosofia ubuntu. In. Problemata: Revista internacional de filosofia. V. 10. n. 2, 2019, p. 93-110. Disponível em https://periodicos.ufpb.br/ojs/index.php/problemata/issue/view/2407. Acesso em 13.07.2020.

URASSE, Anin. Uma introdução aos 18 princípios do Mulherismo Africana. In. PANAFRICANISTAS, União dos Coletivos. Coleção Pensamento Preto: Epistemologias do Renascimento Africano [Volume III]. Diáspora Africana: Editora Filhos da África, 2019, p.302-315.

WALSH, Catherine. Interculturalidade crítica e educação intercultural. La Paz, 2009. Disponível em https://pt.scribd.com/document/227507643/Interculturalidade-Critica-eEducacao-Intercultural-Carherine-Walsh . Acesso em 13.07.2020. 